\title{
Effect of Sucralfate on Components of Mucosal Barrier Produced by Cultured Canine Epithelial Cells in Vitro
}

\author{
JAMES M. SCHEIMAN, MD, EUGENE R. KRAUS, MS, KENJI YOSHIMURA, MD, \\ and C. RICHARD BOLAND, MD
}

\begin{abstract}
The mucous gel maintains a neutral microclimate at the epithelial cell surface, which may play a role in both the prevention of gastroduodenal injury and the provision of an environment essential for epithelial restitution and regeneration after injury. Enhancement of the components of the mucous barrier by sucralfate may explain its therapeutic efficacy for upper gastrointestinal tract protection, repair, and healing. We studied the effect of sucralfate and its major soluble component, sucrose octasulfate (SOS), on the synthesis and release of gastric mucin and surface active phospholipid, utilizing an isolated canine gastric mucous cells in culture. We correlated these results with the effect of the agents on mucin synthesis and secretion utilizing explants of canine fundus in vitro. Sucralfate and SOS significantly stimulated phospholipid secretion by isolated canine mucous cells in culture (123\% and $112 \%$ of control, respectively). Indomethacin pretreatment significantly inhibited the effect of sucralfate, but not SOS, on the stimulation of phospholipid release. Administration of either sucralfate or SOS to the isolated canine mucous cells had no effect upon mucin synthesis or secretion using a sensitive immunoassay. Sucralfate and SOS did not stimulate mucin release in the canine explants; sucralfate significantly stimulated the synthesis of mucin, but only to $108 \%$ of that observed in untreated explants. No increase in $P G E_{2}$ release was observed after sucralfate or SOS exposure to the isolated canine mucous cells. Our results suggest sucralfate affects the mucous barrier largely in a qualitative manner. No increase in mucin secretion or major effect on synthesis was noted, although a significant increase in surface active phospholipid release was observed. The lack of dose dependency of this effect, along with the results of the $P G E_{2}$ assay, suggests the drug may act through a non-receptor-mediated mechanism to perturb the cell membrane and release surface active phospholipid. The enhancement of phospholipid release by sucralfate to augment the barrier function of gastric mucus may, in concert with other effects of the drug, strengthen mucosal barrier function.
\end{abstract}

KEY WORDS: gastric mucin; surface active phospholipid; prostaglandins.

\footnotetext{
Manuscript received January 29, 1992; revised manuscript received April 24, 1992; accepted May 14, 1992.

From the Research Service, Ann Arbor VA Medical Center and GI Peptide Research Center, Department of Internal Medicine, University of Michigan Medical School, Ann Arbor, Michigan 48105 .

Supported in part by the Michigan Gastrointestinal Peptide Research Center grant (5P30-DK34933), the NIH-DDK grant (R01-DK37989), and a gift from Chugai Pharmaceutical Com-
}

pany. Presented in part at the annual meeting of the American Gastroenterological Association in 1989 (Gastroenterology 94:A446, 1989). The pharmaceutical company had no input into the study design, analysis of results, nor review of the manuscript prior to publication.

Address for reprint requests: Dr. James M. Scheiman, GI Section (111D), VA Medical Center, 2215 Fuller Road, Ann Arbor, Michigan 48105. 
The maintenance of the integrity of the gastroduodenal mucosa is complex. Of critical importance is the mucous layer, which is composed of a mucin gel associated with other proteins and lipids into which a bicarbonate-rich fluid is secreted forming a protective $\mathrm{pH}$ gradient (1). The ability of the mucous gel to maintain a neutral microclimate at the cell surface may play a role not only in the prevention of injury to the intact epithelium but also in the generation of an environment suitable for epithelial restitution and regeneration after injury. Long-term preservation of this mucosal barrier depends on continued synthesis and secretion of its components: mucin, lipids, and bicarbonate. Enhancement of the components of the mucosal barrier by sucralfate may explain its effect in upper gastrointestinal tract protection, repair, and healing (2).

The lipid component of the mucous gel appears to be critical for its function as a physiological barrier. Phospholipids, while accounting for a small percentage of the total lipids associated with gastric mucus glycoprotein, had the greatest quantitative effect on the ability of the mucus to retard $\mathrm{H}^{+}$ diffusion in vitro (3). The viscoelastic properties of mucin correlated with its ability to retard $\mathrm{H}^{+}$diffusion and depended upon hydrophobic domains of the mucin protein core and the carbohydrate side chains of the mucin molecule (4). The hydrophobic regions in gastric mucin are important for lipid binding. The lipids bound to mucin have recently been demonstrated to protect mucin from oxyradical attack, further supporting the protective role of lipids in the protective mucous gel (5).

An evolving body of literature has suggested that the phospholipid component of the mucosal barrier plays a major role in epithelial defense. The ability of a liposomal suspension containing surface active phospholipids administered orally to prevent injury in pylorus ligated rats before challenge with acid has focused considerable attention upon the role of phospholipids in mucosal defense (6). The surface of the mammalian gastric mucosa has been noted to be uniquely hydrophobic and thus nonwettable to luminal acid (7). The role of surface hydrophobicity in the barrier function of the gastric mucosa has been suggested by observing its attenuation after the administration of barrier breakers such as bile salts and aspirin, and its enhancement by protective agents such as prostaglandins (8). The predominant surface active phospholipid in pulmonary surfactant is dipalmitoylphosphatidylcholine (DPPC). The gastric mucosa has been observed to contain substan- tial levels of this surface active phospholipid (9). This amphipathic molecule is comprised of two saturated fatty acids that allow the creation of a tightly packed phospholipid monolayer film, which forms a hydrophobic barrier to gastric acid. Although early descriptions of the hydrophobic barrier hypothesized that a film composed of DPPC directly upon the epithelial cell surface (10), later work has clarified the role of the mucous gel as the locus of surface hydrophobicity $(11,12)$. Work in our laboratory has confirmed that mucous cells synthesize and secrete DPPC in vitro and has suggested that phospholipid secretion is linked to mucin secretion (13), augmenting the mucous gel and its ability to resist acid.

Previous studies regarding the effect of sucralfate on the mucosal barrier have been limited. Utilizing a histochemical technique to measure mucus output in rhesus monkeys, sucralfate stimulated the output of soluble mucus; this stimulation was not attenuated by cyclooxygenase inhibition (14). Similarly, sucralfate stimulated human gastric bicarbonate secretion, but this too appeared to be independent of its ability to stimulate prostaglandin generation (15). These studies suggest that sucralfate may have direct effects upon the mucosal barrier, unlike its well-studied role in cytoprotection, which is largely dependent upon prostaglandin generation.

Our laboratory has developed an isolated canine gastric mucous cell culture system to study the physiological regulation of the mucous barrier, and we have developed a specific enzyme-linked immunosorbent assay (ELISA) for gastric mucin (16). Utilizing this system, we studied the direct effect of sucralfate and its major soluble component, sucrose octasulfate (SOS), on the synthesis and release of mucin and phospholipid. We correlated these results with the effect of sucralfate on mucin synthesis and secretion utilizing explants of canine fundus in vitro.

\section{MATERIALS AND METHODS}

The following reagents were purchased from Sigma Chemical Company (St. Louis, Missouri): Hanks' balanced salt solution (HBSS), bovine serum albumin (BSA), Ham's F12-Dulbecco's modified Eagle's culture medium (F12/DME), $N$-2-hydroxyethylpiperazine- $N^{\prime}-2-$ ethanesulfonic acid (HEPES), glutamine, collagenase III, calcium/magnesium-free Earle's balanced salt solution (EBSS), Sepharose CL-4B, antibiotics for cell culture, Tween-20, ethylenediaminetetraacetic acid (EDTA), 3,3'diaminobenzidine (DAB), dimethyl sulfoxide (DMSO), indomethacin, carbamylcholine chloride (carbachol), 
phosphotungstic acid (PTA), 2,2'-azino-bis-(3-ethylbenzthiazoline-bisulfonic acid) (ABTS). Trichloracetic acid (TCA) was purchased from Fisher Scientific (Livonia, Missouri). Diethyl-ether was purchased from Mallinckrodt, Inc. (Paris, Kentucky). Fetal bovine serum (FBS) was purchased from Hyclone (Logan, Utah). Silica gel plates were purchased from Merck (Darmstadt, Germany). The radionuclides $\left[{ }^{3} \mathrm{H}\right]$ glucosamine $(8-30 \mathrm{Ci} / \mathrm{mmol})$, and $\left[{ }^{3} \mathrm{H}\right]$ methyl choline chloride $(86.7 \mathrm{Ci} / \mathrm{mMol})$ were purchased from New England Nuclear Research Products (Wilmington, Delaware). The goat anti-rabbit antibody and the Streptavidin-peroxidase reagent were purchased from Zymed Laboratories (South San Francisco, California). The plates used for the immunosorbent assays were 96-well, flat-bottom, tissue culture plates purchased from Costar (Cambridge, Massachusetts), which were read using a Titertek Multiscan plate reader (Flow Laboratories, McLean, Virginia). Sucralfate and sucrose octasulfate (SOS) powder were gifts of Marion Laboratories (Kansas City, Missouri).

Preparation of Primary Culture of Canine Fundic Surface Epithelial Cells. Dispersed canine gastric epithelial cells were prepared by the method of Soll as previously described (16). In brief, the stomach was removed from an anesthetized mongrel dog, the gastric epithelium stripped away and minced, and the cells dispersed using EDTA and collagenase. The dispersed cells were separated into different fractions according to cell size using the counterflow elutriation centrifuge (Beckman Instruments, Arlington Heights, Illinois). By varying the rotor speed and elutriation buffer flow rate, five cell fractions were generated as a function of cell diameter and have been termed $\mathrm{C} 1, \mathrm{C} 2,3, \mathrm{C} 4,5, \mathrm{C} 6,7$, and $\mathrm{C} 8,9$. Fraction $\mathrm{C} 1$ contains bacteria and cell fragments and was discarded. Previous studies have demonstrated that fraction C2,3 is enriched in endocrine and mast cells along with mucous cells (16). Mucous cells are enriched in C4,5 and C6,7, while chief cells are present in C4,5, C6,7, and C8,9, with the greatest content in $\mathrm{C} 6,7$. Parietal cells are present principally in $\mathrm{C} 8,9$. Based upon our previous experience (13), we chose $C 4,5$, the fraction most enriched with mucous cells, for study.

Metabolic Labeling of Mucin-Associated Phosphatidylcholine. The cells were seeded into 12 -well plastic tissue culture plates with approximately $4 \times 10^{6}$ cells in $2-3 \mathrm{ml}$ of tissue culture media per well, and cultured at $37^{\circ} \mathrm{C}$ in $5 \% \mathrm{CO}_{2}, 95 \%$ humidified air. The cells were allowed to recover from the preparative techniques overnight and labeled by the addition of $\left[{ }^{3} \mathrm{H}\right]$ choline $2 \mu \mathrm{Ci} / \mathrm{ml}(4 \mu \mathrm{Ci}$ total activity), for a $24-\mathrm{hr}$ loading period. The cells were then treated with putative agonist for $1 \mathrm{hr}$. The media and cells were collected separately; floating cells were removed by centrifugation at $1000 \mathrm{~g}$. The $\left[{ }^{3} \mathrm{H}\right]$ cholinelabeled phosphatidylcholine was isolated as previously described (13). Agonists (sucralfate and SOS) were prepared in $0.2 \mathrm{M}$ phosphate-buffered saline.

Quantitation of gastric mucin by direct ELISA. The isolated cells were cultured in the presence of the putative agonist for $24 \mathrm{hr}$. The media and cells were collected together for quantitation of total mucinlike immunoreactivity. The cells were disrupted with a $5-\mathrm{sec}$ burst from a Labline Ultratip sonicator at a setting of 40-60 W and centrifuged at $2000 \mathrm{~g}$ for $10 \mathrm{~min}$ to remove particulates. This assay has been described in detail previously and measures total mucinlike immunoreactivity (MLI), reflecting antigenic determinants requiring both carbohydrate and protein (16). The ELISA was performed by loading $100 \mu \mathrm{l}$ of mucin-containing sample onto 96 -well microtiter plates and incubating overnight at $37^{\circ} \mathrm{C}$. Each well was then rinsed with "wash buffer" [phosphatebuffered saline (PBS) containing 0.05\% Tween-20] three times and then coated with $200 \mu$ l of $0.5 \%$ crystalline grade bovine serum albumin for $1 \mathrm{hr}$ at $37^{\circ} \mathrm{C}$. Each well was again washed three times with wash buffer, and incubated with $200 \mu \mathrm{l}$ of rabbit anti-gastric mucin antibody (at a dilution of 1:2000) in PBS containing $0.05 \%$ Tween-20 for $1 \mathrm{hr}$ at $37^{\circ} \mathrm{C}$. This was rinsed three times with wash buffer, $200 \mu$ l of biotinylated goat anti-rabbit antibody was added for $1 \mathrm{hr}$ at $37^{\circ} \mathrm{C}$, rinsed three times with wash buffer, and $200 \mu$ l of Streptavidin-horseradish peroxidase at a concentration of $40 \mu \mathrm{g} / \mathrm{well}$ in PBSTween, $\mathrm{pH} 6.5$, was added for $1 \mathrm{hr}$ at $37^{\circ} \mathrm{C}$. Each well was rinsed three times with wash buffer, and color developed by adding ABTS $(0.01 \mathrm{~g} / 25 \mathrm{ml})$ in $100 \mathrm{mM}$ sodium citrate buffer, $\mathrm{pH} 4.2$, plus $75 \mu \mathrm{l}$ of $30 \% \mathrm{H}_{2} \mathrm{O}_{2}$ / $\mathrm{ml} / 25 \mathrm{ml}$ buffer (added immediately prior to use) for 5 min, in the dark. The antibody binding was determined by reading the color developed at $414 \mathrm{nM}$ using a Titertek Multiscan multiwell plate reader.

Indirect ELISA (I-ELISA). This technique is a modification of the method of Mantle et al., which complements the above-described direct ELISA and has proven sensitive for quantitation of small quantities of mucin (17). Microtiter plate wells were coated overnight with $500 \mathrm{ng}$ (dry mass) purified canine fundic mucin. The wells were washed with PBS containing $0.05 \%$ Tween-20 and the remaining nonspecific binding sites blocked by adding 200 $\mu \mathrm{l}$ of $0.5 \%$ bovine serum albumin. One hundred microliters of mucin standards (purified mucin $10 \mu \mathrm{g} / \mathrm{ml}-10$ $\mathrm{ng} / \mathrm{ml}$ ) and $100 \mu \mathrm{lmucin}$-containing samples were preincubated with $100 \mu$ l antibody (1:6000 dilution) overnight at $37^{\circ} \mathrm{C}$, and $75 \mu \mathrm{l}$ was transferred to the mucin-coated wells. The wells were washed and biotinylated secondary antibody, Streptavidin-horseradish peroxidase, and ABTS were added as described above. I-ELISA was utilized to quantitate mucin secretion in an aliquot of media from isolated cells.

Glycoprotein Synthesis and Secretion in Canine Fundus Explants. In separate experiments designed to examine the response of more intact epithelium to stimulation, the stomach was removed and the mucosal layer was cut into small pieces $(2 \times 2 \mathrm{~mm})$. Ten tissue pieces were placed in each tissue culture well $(35 \mathrm{~mm}$ diameter) with $2 \mathrm{ml}$ of medium consisting of F12/DME, L-glutamine, $15 \mathrm{mM}$ HEPES, 7.5\% FBS, 7.5\% heat-inactivated dog serum, and $0.05 \mathrm{mg} / \mathrm{ml}$ gentamicin. The explants were incubated in the presence of $5 \mu \mathrm{Ci} /$ well of $\left[{ }^{3} \mathrm{H}\right]$ glucosamine at $37^{\circ} \mathrm{C}$ under $5 \% \mathrm{CO}_{2}-95 \%$ air for $24 \mathrm{hr}$. The medium was then removed and fresh medium added with putative agonist for $6 \mathrm{hr}$. After $2 \mathrm{hr}$ of incubation, an aliquot of the medium was removed for assay of secreted glycoprotein, and after $6 \mathrm{hr}$ of agonist exposure the media and tissue fragments were harvested together for quantitation of labeled glycoprotein. 
Assessment of Glycoprotein Synthesis. At the end of the period of incubation, media and tissue fragments were harvested together. After homogenization and sonication, they were centrifuged at $100,000 \mathrm{~g}$ at $4^{\circ} \mathrm{C}$ for $1 \mathrm{hr}$ to remove cellular debris. The supernatant was collected and the glycoprotein was quantitated. The supernatant was precipitated with $10 \% \mathrm{TCA}$ and $1 \%$ PTA at $4^{\circ} \mathrm{C}$ overnight. Then the samples were centrifuged at $500 \mathrm{~g}$ for $25 \mathrm{~min}$ and the pellets were resuspended by sonication. Each pellet was washed three times with $10 \%$ TCA $1 \%$ PTA and twice with ether-ethanol (3:1). The pellets were dissolved in $2 \mathrm{ml}$ of $0.6 \mathrm{M} \mathrm{KOH}$ and ${ }^{3} \mathrm{H}$ radioactivity was measured.

Measurement of Prostaglandin $\mathbf{E}_{2}$. Five hundred microliters of 2-ml media was collected from each unlabeled well before and $2 \mathrm{hr}$ after the culture was exposed to agonists and immediately frozen at $-70^{\circ} \mathrm{C}$. $\mathrm{PGE}_{2}$ in media was quantitated by the University of Michigan Diabetes Center, Ligand Core Laboratory, utilizing the enzyme immunoassay technique (Cayman Chemical, Ann Arbor, Michigan).

The $\mathrm{PGE}_{2}$ antibody was purchased commercially from Cayman Chemical Company. Cross-reactivities with other prostaglandins are as follows: $15-$ keto-PGE $2,9.2 \%$; $\mathrm{PGE}_{1}, 5 \%$; cross-reactivities were less than $0.2 \%$ for the following prostaglandins: $\mathrm{PGA}_{1}, \mathrm{PGB}_{1}, \mathrm{PGB}_{2}, \mathrm{PGD}_{2}$, $\mathrm{PGF}_{1 \alpha}$, 6-keto-PGF ${ }_{1 \alpha}, \mathrm{PGF}_{2 \alpha}$, 13,14-dihydro-15-keto$\mathrm{PGF}_{2 \alpha}$, and thromboxane $\mathrm{B}_{2}$ (manufacturer specifications). $\mathrm{PGE}_{2}$ generation was calculated by subtracting time zero from the 2 -hr value to correct for carry over during tissue preparation.

Data Analysis. The release of mucin-associated phospholipid after agonist treatment was expressed as cpm in the medium divided by the total cpm incorporated (ie, percentage of cell content released). The secretion of glycoprotein by cultured explants was quantitated in an identical fashion, total mucin synthesis was estimated by the addition of secreted and tissue associated glycoprotein. Differences between treated and control wells were expressed as percentage of control and analyzed by the Student's $t$ test for paired data. Differences in mucin-like immunoreactivity and increases in $\mathrm{PGE}_{2}$ levels in treated and control wells were analyzed similarly.

\section{RESULTS}

Effects on Phospholipid Secretion. The effect of sucralfate and SOS on the release of surface active phospholipid by cultured mucous cells is shown in Figure 1. Sucralfate, only in the lowest dose tested, led to a significant increase in phospholipid secretion (123\% of control, $P=0.02$ ). Indomethacin pretreatment significantly decreased the stimulatory effect of sucralfate on phospholipid secretion to $110 \%$ of control, $P=\mathbf{0 . 0 3}$. SOS, in a non-dosedependent manner, also stimulated phospholipid secretion, to $112 \%$ of control at $10^{-6} \mathrm{M}$ (Figure 2). Indomethacin pretreatment had no significant effect upon the ability of SOS to release phospholipid.

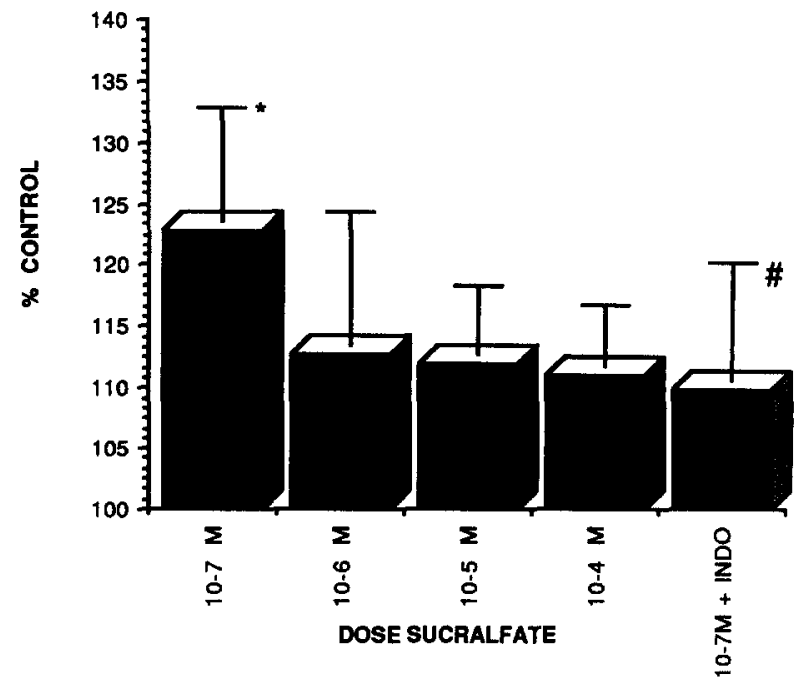

Fig 1. Effect of sucralfate $\left(10^{-7}-10^{-4} \mathrm{M}\right)$ on phospholipid release by isolated canine gastric mucous cells in culture. INDO = indomethacin $10^{-5} \mathrm{M}^{*} P=0.02{ }^{*} P=0.03$ vs sucralfate $10^{-7} \mathrm{M}$. Values are mean \pm standard error, $N \geq 5$.

These data suggest that sucralfate may act through two mechanisms: a direct effect of SOS on the mucous cell and an indirect effect, perhaps linked to eicosanoid generation.

Effects on Mucin Synthesis and Secretion. Exposure of isolated mucous cells in culture to sucralfate $\left(10^{-3}-10^{-7} \mathrm{M}\right)$ or SOS $\left(10^{-4}-10^{-7} \mathrm{M}\right)$ for $24 \mathrm{hr}$ had no effect on mucin synthesis quantitated by ELISA $(N=5)$. Utilizing the indirect ELISA to estimate the effect on mucin secretion, neither sucralfate $10^{-4}-10^{-7} \mathrm{M}$ nor SOS $10^{-4}-10^{-7} \mathrm{M}$, significantly stimulated mucin secretion above the increase ob-

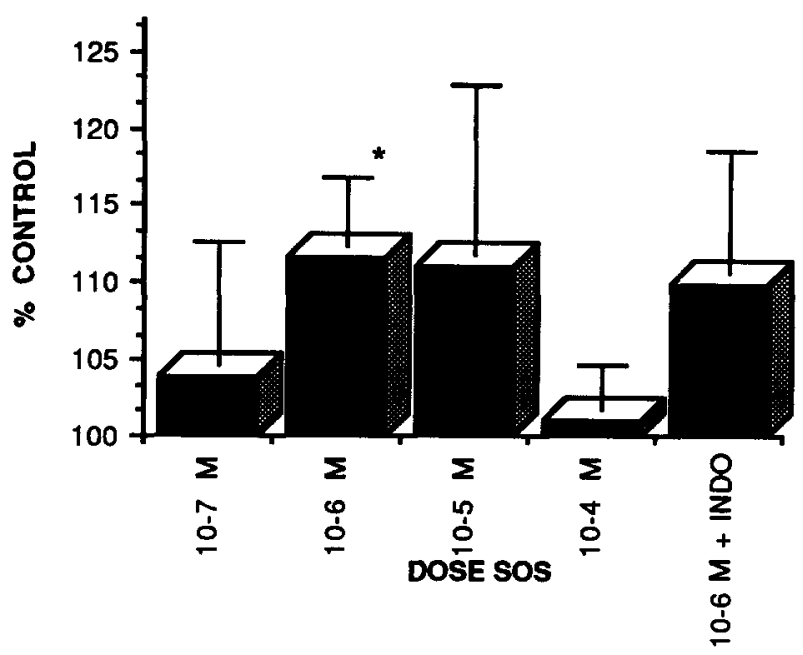

Fig 2. Effect of SOS $\left(10^{-7}-10^{-4} \mathrm{M}\right)$ on phospholipid release by isolated canine gastric mucous cells in culture. INDO $=$ indomethacin $10^{-5}$ M. $P=0.02$. Values are mean \pm standard error, $N \geq 5$.

Digestive Diseases and Sciences, Vol. 37, No. 12 (December 1992) 
Table 1. Glycoprotein Synthesis and Secretion in Canine Fundic MuCOSAL EXPLANTS*

\begin{tabular}{lcccc}
\hline & $\begin{array}{c}\text { Cell content } \\
\text { secreted } \\
\text { Agent }\end{array}$ & $\begin{array}{c}\text { P vs } \\
\text { control }\end{array}$ & $\begin{array}{c}\text { Glycoprotein } \\
\text { synthesis per } \\
\text { well }(\text { dpm })\end{array}$ & $\begin{array}{c}\text { P vs } \\
\text { control }\end{array}$ \\
\hline Control & $26 \pm 2$ & & $1886 \pm 227$ & \\
Sucralfate $10^{-7} \mathrm{M}$ & $27 \pm 2$ & NS & $2032 \pm 183$ & 0.04 \\
SOS $10^{-6} \mathrm{M}$ & $28 \pm 3$ & NS & $1904 \pm 253$ & NS \\
\hline *Radiolabeled glycoprotein in the media and explants were quantitated by acid \\
precipitation. $N=6$.
\end{tabular}

served in untreated wells $(1.52 \pm 0.30$ to $1.77 \pm 0.34$ $\mu \mathrm{g} / \mathrm{ml}$ ), while carbachol $10^{-5} \mathrm{M}$ stimulated mucin secretion from $1.52 \pm 0.30$ to $2.21 \pm 0.42 \mu \mathrm{g} / \mathrm{ml}(P$ $=0.01, N=5$ ).

Mucin synthesis was also studied utilizing nondissociated canine fundic mucosal explants. Table 1 expresses the results for glycoprotein secretion and synthesis in response to sucralfate and SOS. No significant effect on glycoprotein secretion was observed in response to sucralfate or SOS to the doses tested. With regard to total $\left[{ }^{3} \mathrm{H}\right]$ glucosamine incorporated into acid precipitable glycoprotein, sucralfate $10^{-7} \mathrm{M}$, stimulated synthesis minimally to $108 \%$ of that observed in untreated explants $(N=$ $6)$.

PGE $_{2}$ Release. Isolated canine cells were exposed to sucralfate $10^{-7} \mathrm{M}, \operatorname{SOS} 10^{-6} \mathrm{M}$, or vehicle (PBS) for $24 \mathrm{hr}$ in culture. $\mathrm{PGE}_{2}$ concentrations were measured by RIA before and after drug exposure as shown in Table 2. No significant increase in $\mathrm{PGE}_{2}$ generation was observed in response to any stimulation $(N=4)$.

\section{DISCUSSION}

Sucralfate neither neutralizes secreted acid nor alters acid secretion. Therefore, its ability to heal gastric and duodenal ulcers has generated interest in its mechanism of action. Investigators have identified multiple actions of sucralfate, which may explain its ability to present acute mucosal injury (cytoprotective effects), and promote epithelial repair and healing. As discussed in a recent review (18), sucralfate has been demonstrated to affect arachidonic acid metabolism, mucus and bicarbonate secretion, and tissue growth, regeneration, and repair. Sucralfate also has in vitro antipeptic effects and may provide a physical barrier (as a polyanion gel) between luminal contents and the mucosa, impairing the diffusion of acid, pepsin, bile, and phospholipases. The relative importance of each of these actions to explain the therapeutic efficacy of sucralfate remains unknown.

Sucralfate is also an effective agent for the prophylaxis of ulcer recurrence (18). This observation suggests the drug may augment those factors important in primary epithelial mucosal defense. The mucus coat lining the gastric surface epithelium provides the first line of defense against the acidpeptic activity in the lumen. This mucous gel is composed of mucin associated with other proteins and lipids (particularly surface active phospholipids) into which bicarbonate is secreted, forming a protective $\mathrm{pH}$ gradient. Acid secretion occurs in a pulsatile fashion through the mucus gel, allowing maintenance of the $\mathrm{pH}$ of the mucosa near neutrality despite the very low luminal $\mathrm{pH}(19)$. Since sucralfate does not affect acid secretion, its effects on the mucosal barrier must be involved in any attempt to explain its therapeutic efficacy.

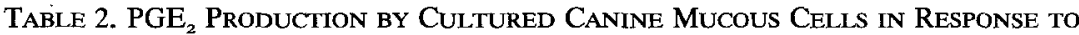
SUCRALFATE OR SOS*

\begin{tabular}{lcclc}
\hline Agent & $\begin{array}{c}\text { Pretreatment } \\
(\mathrm{pg} / \mathrm{ml})\end{array}$ & $\begin{array}{c}\text { Posttreatment } \\
(\mathrm{pg} / \mathrm{ml})\end{array}$ & -Fold increase & $\begin{array}{c}\text { P value } \\
\text { vs } \\
\text { control }\end{array}$ \\
\hline Control & $4648 \pm 1257$ & $38,724 \pm 11,670$ & $7.81 \pm 95$ & \\
Sucralfate $10^{-7} \mathrm{M}$ & $4607 \pm 1294$ & $33,365 \pm 10,377$ & $7.53 \pm 1.16$ & NS \\
SOS $10^{-6} \mathrm{M}$ & $4637 \pm 1211$ & $31,678 \pm 8,814$ & $7.00 \pm 2.04$ & NS \\
\hline
\end{tabular}

*Medium was collected immediately before and $2 \mathrm{hr}$ after drug exposure. PGE $_{2}$ levels were measured by RIA. $N=4$. 
This study has investigated the effect of sucralfate upon components of the mucus gel utilizing isolated canine mucous cells in culture and tissue explants. We have successfully utilized this model previously to probe the physiologic regulation of gastric mucin synthesis and surfactant phospholipid secretion $(13,16)$. We observed no direct effect of sucralfate or SOS on mucin production or secretion by isolated cells in culture. Our data in explant culture confirmed these results with the exception of a modest increase of $8 \%$ in $\left[{ }^{3} \mathrm{H}\right]$ glucosamine incorporation into glycoprotein. Our results differ somewhat from other published work on the effect of sucralfate on gastric mucus. Prior studies have utilized techniques such as total carbohydrate measurements of aspirated mucus or histochemical techniques $(14,20)$, neither of which are sufficiently specific for mucin glycoproteins. These techniques are also limited by the effect of sucralfate to influence bicarbonate output, which may influence the recovery of carbohydrates or increase the apparent increase in thickness of secreted mucous gel.

Our results also differ from those of Slomiany et al. (21), who utilized rat epithelial cells exposed to sucralfate in vivo, then observed a marked stimulation of glycoprotein synthesis from tissue explants in vitro. We observed modest stimulation of glycoprotein synthesis by sucralfate in explants; the difference in magnitude may reflect both species differences and our technique of drug exposure in culture only. It is also possible that the glycoprotein increased by sucralfate in the present and prior work is not mucin, since this is the first study to use a specific immunoassay for gastric mucin for this purpose. The lack of effect upon mucin synthesis and secretion in isolated cells points to the requirement of an intermediate messenger in intact mucosa. Based upon our $\mathrm{PGE}_{2}$ results, the intermediate for sucralfate action may be another eicosanoid or peptide, such as EGF. EGF may stimulate PG production by mucosal macrophages (22) and has been demonstrated to mediate certain protective effects of sucralfate (23).

We observed that sucralfate and SOS significantly increased surfactant phospholipid release by cultured mucous cells. The effect of sucralfate was partially inhibited by indomethacin, while the effect of SOS was not, suggesting that sucralfate may enhance phospholipid release by the direct effect of SOS and an indirect effect of sucralfate to stimulate eicosanoid formation. Our inability to measure an increment in $\mathrm{PGE}_{2}$ levels after administration of sucralfate and SOS is difficult to explain, especially in light of the ability of indomethacin to blunt the effect of sucralfate on phospholipid release. Sucralfate may stimulate phospholipid release via another mechanism sensitive to cyclooxygenase inhibition such as through a different prostaglandin or a leukotriene. The effects of sucralfate and SOS were not dose-dependent. This may reflect the insolubility of sucralfate in buffered media; furthermore, larger doses of sucralfate left a layer of insoluble drug in the well, which may have altered the response of the cells. Of interest, the highest dose of SOS $\left(10^{-4} \mathrm{M}\right)$, showed no additional increment in phospholipid release. Sucralfate and SOS may also act, at least partially, in a non-dose-dependent fashion by its irritative manner to cause phospholipid (and possibly mucus or eicosanoid) release.

Our findings may explain the recent morphological observation that sucralfate increases the presence of surface active phospholipid in lamellar bodies found in the gastric lumen of rats (24). This corresponds to the observation that sucralfate increases the viscosity and hydrophobicity of mucin and decreases its permeability to $\mathrm{H}^{+}(25)$. Although other investigators have not observed an enhancement in mucus phospholipid content in the rat in response to sucralfate, these investigators utilized entirely different techniques and species (26).

The implications of the present study suggest sucralfate may affect the gastric mucosal barrier in a largely qualitative manner. Increasing surface active phospholipid secretion may enhance the barrier function of gastric mucus. Previous work by other investigators has suggested that sucralfate may interact directly with gastric mucus to enhance its viscosity and resistance to $\mathrm{H}^{+}$permeation on a physical basis (27). The mechanism through which sucralfate and SOS act on the mucous cell is still unclear. Our studies do not implicate $\mathrm{PGE}_{2}$ as an important intermediate for the synthesis or release of mucin; the dose relationship raises doubt regarding the presence of a specific receptor for sucralfate or SOS. Our data suggest the drug may work as a local irritant, perhaps causing direct membrane pertubation, the generation of secondary messengers, and effects on the mucus barrier. This hypothesis is consistent with the previous observation that sucralfate activates phosphoinositide turnover in the gastric mucosa (21). Additional efforts are required to understand the action of sucralfate at the cellular level. Sucralfate and SOS have minimal effects on isolated gastric mucous cells. The com- 
plexity of gastric epithelium suggests that one must also address issues of submucosal blood flow, cellular restitution, and other processes that require the intact organ for an integrated response.

\section{REFERENCES}

1. Miller TA: Gastroduodenal mucosal defense: Factors responsible for the ability of the stomach and duodenum to resist injury. Surgery 103:389-397, 1988

2. Szabo S, Hollander D: Pathways of gastrointestinal protection and repair: Mechanisms of action of sucralfate. Am J Med 86(suppl 6A):23-31, 1989

3. Sarosiek J, Slomiany A, Takagi A, Slomiany BL: Hydrogen ion diffusion in dog gastric mucous glycoprotein: Effect of associated lipids and covalently bound fatty acids. Biochem Biophys Res Commun 118:523-531, 1983

4. Slomiany BL, Sarosiek J, Slomiany A: Role of carbohydrates in the viscosity and permeability of gastric mucin to hydrogen ion. Biochem Biophys Res Commun 142:783-790, 1987

5. Gong D, Turner B, Bhsakar KR, Lamont JT: Lipid binding to gastric mucin: Protective effect against oxygen radicals. Am J Physiol 259:G681-686, 1990

6. Lichtenberger LM, Graziani LA, Dial EJ, Butler BD, Hills BA: Role of surface-active phospholipids in gastric cytoprotection. Science 219:1307-1309, 1983

7. Butler BD, Lichtenberger LM, Hills BA: Distribution of surfactants in the canine gastrointestinal tract and their ability to lubricate. Am J Physiol 244:G645-G651, 1983

8. Lichtenberger LM, Richards JE, Hills BA: Effect of 16,16dimethyl prostaglandin $E_{2}$ on the surface hydrophobicity of aspirin-treated canine gastric mucosa. Gastroenterology 88:308-314, 1985

9. Wassef MK, Lin YN, Horowitz MI: Molecular species of phosphatidylcholine from rat gastric mucosa. Biochim Biophys Acta 573:222-226, 1979

10. Hills BA, Butler BD, Lichtenberger LM: Gastric mucous barrier: Hydrophobic lining to the lumen of the stomach. Am J Physiol 244:G561-G568, 1983

11. Goddard PJ, Kao YJ, Lichtenberger LM: Lumenal surface hydrophobicity of canine gastric mucosa is dependent on a surface mucous gel. Gastroenterology 98:361-370, 1990

12. Kao YJ, Goddard PJ, Lichtenberger LM: Morphological effects of aspirin and prostaglandin on the canine gastric mucosal surface: Analysis with a phospholipid-selective cytochemical stain. Gastroenterology 98:592-606, 1990

13. Scheiman JM, Kraus ER, Bonnville LA, Weinhold PA,
Boland CR: Synthesis and prostaglandin $\mathrm{E}_{2}$-induced secretion of surfactant phospholipid by isolated gastric mucous cells. Gastroenterology 100:1232-1240, 1991

14. Shea-Donohue T, Steel L, Montcalm E, Dubois A: Gastric protection by sucralfate: Role of mucus and prostaglandins. Gastroenterology 91:660-666, 1986

15. Shorrock CJ, Rees WDW: Effect of sucralfate on human gastric bicarbonate secretion and local prostaglandin $E_{2}$ metabolism. Am J Med 86(suppl 6a):2-4, 1989

16. Boland CR, Kraus ER, Scheiman JM, Black C, Deshmukh GD, Dobbins WO: Characterization of mucous cell synthetic functions in a new primary canine mucous cell culture system. Am J Physiol 258:G774-G787, 1990

17. Mantle M, Forstner GG, Forstner JF: Antigenic and structural features of goblet cell mucin of human small intestine. Biochem J 217:159-167, 1984

18. McCarthy DM: Sucralfate N Engl J Med 325:1017-1025, 1991

19. Holm L, Flemstrom G: Microscopy of acid transport at the gastric surface in vivo. J Intern Med 228(suppl 1):91-95, 1990

20. Tarnawski A, Hollander D, Krause WJ, Zipser RD, Stachura J, Gergely H: Does sucralfate affect the normal gastric mucosa? Histologic, ultrastructural and functional assessment in the rat. Gastroenterology 90:893-905, 1986

21. Slominany BL, Piltrowski J, Tamura S, Slomiany A: Enhancement of the protective qualities of gastric mucus by sucralfate: Role of phosphoinositides. Am J Med 91(suppl 2A):30S-36S, 1991

22. Chen MC, Sanders MJ, Amirian DA, Thomas LP, Kauffman $G$, Soll AH: Prostaglandin $E_{2}$ production by dispersed canine fundic mucosal cells: Contribution of macrophages and endothelial cells a major sources. J Clin Invest 84:15361549, 1989

23. Nexo E, Poulsen SS: Does epidermal growth factor play a role in the action of sucralfate? Scand J Gastroenterol 22(suppl 127):45-49, 1987

24. Hills BA: A common physical basis for the gastric mucosal barrier and the action of sucralfate. Am J Med 91(suppl 2A):43S-51S, 1991

25. Slomiany BL, Laszewicz W, Slomiany A: Effect of sucralfate on the viscosity of gastric mucus and the permeability to hydrogen ion. Digestion 33:146-151, 1986

26. Slomiany BL, Piotrowski J, Okazake K, Grzelinska E, Slomiany A: Nature of the enhancement of the protective qualities of gastric mucus by sucralfate. Digestion 44:222231, 1989

27. Tasman-Jones C, Morrison G, Thomsen L: Sucralfate interactions with gastric mucus. Am J Med 86(suppl 6A):5-9, 1989 